\title{
Situation of Integrated Eldercare Services with Medical Care in China
}

\begin{abstract}
ZHENG WANG ${ }^{1}$, HUA LI $^{2}$, XUANXUAN WANG ${ }^{3,4}$, XIAN AN $^{5}$, GUANGJIE LI $^{6}$, LEI XUE7 ${ }^{7}$ XIAOWEI WU ${ }^{8 *}$ AND XUN GONG ${ }^{9}$
Key Laboratory of Environmental Pollution Monitoring and Disease Control, Ministry of Education, Guizhou Medical University, Guiyang 550025, ${ }^{1}$ Research Center for Healthcare Management, School of Economic and Management, Tsinghua University, Beijing 100084, ${ }^{2}$ Nursing Department of Cadre sanatorium of Hainan \& Geriatric hospital of Hainan, ${ }^{3}$ Department of Integrated TCM \& Western Medicine, Hubei Cancer Hospital, Tongji Medical College, Huazhong University of Science and Technology, Wuhan, Hubei, ${ }^{4}$ Clinical College of Chinese Medicine, Hubei University of Chinese Medicine, Wuhan, Hubei, ${ }^{5}$ China Nuclear Engineering Consulting Co. Ltd., Beijing, ${ }^{6}$ Medical Service Division of Cadre sanatorium of Hainan \& Geriatric hospital of Hainan (CSH), Haikou, ${ }^{7}$ Institute for Hospital Management, Tsinghua University, Beijing, ${ }^{8}$ Department of Thoracic Surgery, TongJi Hospital, TongJi Medical College, Huazhong University of Science and Technology, Wuhan, Hubei, ${ }^{9}$ Center for civil-military inosculation and development of new material industry in Huludao City, Huludao, China
\end{abstract}

Wang et al.: Situation of Integrated Eldercare Services in China

There are clinics around nursing homes in foreign countries or family doctors for every elderly. When a disease occurs, doctors can provide door to door service to help patients. Since the epidemic of coronavirus disease 2019, the elderly have been a high risk group of people infected with coronavirus disease 2019. In both the United States and Canada, the first recorded coronavirus disease 2019 deaths and outbreaks occurred in nursing homes with case fatality rates in these settings reported to be as high as $33.7 \%$. Due to the lack of adequate medical facilities and adequate medical staff to provide services, the elderly are more likely to be infected with the virus as a result of social interaction. All these show that foreign models can no longer meet the medical needs of the elderly. Therefore, we should take a different perspective and combine pension services with medical care. At present, China is exploring the mode of combination of medical and nursing services. In this study, we investigated the current situation of integrated medical and nursing services in China, exploring the transformation of primary medical institutions into medical and nursing service providers. The integrated eldercare services with medical care is that we make use of the existing medical resources to provide care services, which can meet the health needs of the elderly and reduce the infection rate of the elderly. Using a self-administered or interview questionnaire survey, we conducted t-test and one-way analysis of variance. It was found that the elderly are most satisfied with the geographical location $(90.84 \%)$ and medical services $(90.82 \%)$, and the most dissatisfied with consultation $(87.66 \%)$ and institutional fees $(87.23 \%)$. The elderly with the older age, the higher the monthly income of more than 3000 yuan, marriage and chronic diseases, are highly satisfied with their community health service institutions $(\mathbf{p}<\mathbf{0 . 0 5})$. Through one-way analysis of variance, there were significant differences in medical and health service demand among the groups with different monthly income $(f=5.289$ and 5.312, $p<0.05$ ), different occupation ( $f=5.574$ and $2.325, p<0.05$ ), and different ideal mode of providing for the aged $(f=5.237, p=0.002<0.05)$. By independent sample $t$ test, it was found that there were significant differences in basic medical service demand and health guidance service demand between people with chronic diseases and those without chronic diseases $(p<0.05)$, and those who were willing and unwilling to use information technology for disease management $(p<0.05)$. Through regression analysis, we can see that age $(t=4.411$, $p<0.05)$ and income $(t=2.061, p<0.05)$ have significant influence on basic medical service among the three variables of age, education and monthly income, and the coefficient is positive. Age $(t=2.508, p<0.05)$ and income $(t=3.143, p<0.05)$ had significant influence on rehabilitation guidance service, and the coefficient was positive. In summary, age, income, occupation, whether suffering from chronic diseases, whether they are willing to use information technology to detect and manage diseases and other factors, all affect the demand of the elderly for basic medical services and rehabilitation guidance services in medical service institutions. Through the research on the current situation of the integrated medical and nursing services in China, this study enriches the relevant evidence of the integrated medical and nursing services, and has a certain reference value for the relevant management departments to formulate policiesis.

Key words: Pension, integrated eldercare services with medical care, operation mode

Nursing homes and other long-term care facilities provide care for the most vulnerable people within our society, the majority of them older people with chronic diseases such as dementia ${ }^{[1-4]}$. 
This group has been highly affected by coronavirus disease 2019 (COVID-19). First estimations indicate that in Europe, between $19 \%$ and $72 \%$ of all people who died from COVID-19 lived in nursing homes ${ }^{[5]}$. In the Netherlands, the most recently updated estimations from the electronic patient files indicate that 9785 residents had (suspected) COVID-19. Of those, 1871 have died and 2393 have recovered ${ }^{[5]}$. To prevent and control COVID-19 infections, nursing homes across the world have taken very restrictive measures.

In Canada, in response to the evolving crisis, the Government of Ontario took the extraordinary step of asking hospitals to develop and deploy specialized "COVID-19 Surgical Workforce Access Teams (SWAT)" from hospitals to provide additional staffing, infection prevention and control (IPAC), occupational health, and operational support to nursing homes ${ }^{[6]}$.

InAmerica, the centres for disease control and prevention (CDC) suggest everyday active screening residents for early detection, preventing spread of infection in the facility, and assuring optimized personal protective equipment (PPE) supply to identify those who require transfer to hospital. A geriatric hotline operating $7 \mathrm{~d}$ a w was specifically created for Nursing homes and allows direct interaction between a geriatrician and coordinating physicians or nurses ${ }^{[7]}$.

In Europe, the European centre for disease prevention and control (ECDC), suggested implementing a daily surveillance routine to monitor the residents for typical symptoms and atypical symptoms, as well as signs. The resident or staff with suspected COVID-19 should be tested promptly, and when confirmed, all residents and staff in the facility should undergo weekly or biweekly tests, if available. These measures do not prevent infection, but rather focus on the detection of the first case in the facility and monitoring the following situation. Therefore, more effective procedures are needed to protect the residents from being exposed to the infection being brought into the institution by others: for example, regular testing of staff in advance to avoid a person with symptoms coming to work. Regular staff training is to raise awareness on how to prevent the spread of an infection ${ }^{[8]}$.

In most countries, there are established structures for control of hospital infections: infection control teams, epidemiological nurses, and obligatory staff training on prevention of nosocomial infections ${ }^{[9]}$. Any nursing homes have to move residents to develop COVID units $^{[10]}$.

*Address for correspondence

E-mail: keshuojiao5986@163.com
In France, the government set up out of hospital mobile geriatric medicine team. The teams (consisting of a nurse and a geriatrician) visit nursing homes throughout the Indre-et-Loire region to train the staff in protective hygiene measures, assess the indications for the hospitalization of nursing home residents, and coordinate local healthcare resources around particularly serious cases. And the regional" COVID-19" video conference has been established. A discussion forum has become an essential tool to share information and opinions on COVID-19 crisis management by providing equal levels of access to information on COVID-19 care $^{[11]}$.

At present, from the perspective of the service provider, there were 30000 old age institutions and 7.463 million old age service beds in China by $2018^{[12]}$. Based on this, it is estimated that there are 29.97 old age beds per 1000 elderly people, which is far below the international standard of 50-70 per 1000 elderly people. According to the internationally recognized rule that "three old people need one nurse", the number of nursing staff in China is at least 10 million. However, at present, there are less than 600000 employees in national welfare institutions for the elderly and fewer than 100000 people have qualified for the profession of nursing in old age $e^{[13]}$.

For the demand side of services, China has not yet completed the accumulation of old age support, and the ageing population is not compatible with the level of socio-economic development ${ }^{[14,15]}$. When the developed countries enter the aging society, the Gross Domestic Product (GDP) per capita is more than 10000 dollars, while China is only equivalent to about 9600 dollars (2018). The median per capita disposable income of urban residents in 2018 is 36413 yuan per $\mathrm{y}^{[16]}$. Therefore, the current situation of "one bed is difficult to find" in public pension institutional for the elderly to enter pension institutions ${ }^{[17,18]}$.

The mode of combination of medical and nursing care in China is mainly divided into three types, including the following ${ }^{[19-21]}$ :

This is an open access article distributed under the terms of the Creative Commons Attribution-NonCommercial-ShareAlike 3.0 License, which allows others to remix, tweak, and build upon the work non-commercially, as long as the author is credited and the new creations are licensed under the identical terms

Accepted 26 February 2021

Revised 07 November 2020

Received 15 April 2020 Indian J Pharm Sci 2021;83(1):140-152 
Model of cooperation between medical and nursing institutions: The cooperation model between medical and nursing institutions, that is, the community health service centers cooperate with the nursing institutions in the community to build a medical and nursing cooperation alliance. On the one hand, we will give full play to the professional advantages of community health service centers in health services, health care and other aspects to provide health care for the elderly in the community.

On the other hand, the community based elderly care institutions have also brought into their expertise in providing basic care services for the elderly in the community. The model is relatively common and easy to carry out. It can effectively integrate medical care resources in the community, which not only improves the turnover rate of hospital beds in the community, but also solves the problem of low utilization rate of the beds in the old age institutions.

Radiation model of providing for the aged in medical institutions: The model has combined the specialized medical service points of medical institutions, and integrate the needs of community old age service into their medical service supply system, integrating the functions of old age care within medical institutions. Through specific platforms (such as remote intelligence platform and professional applications), high quality medical resources are brought to grass-roots medical institutions, community families, pension institutions, etc., so as to realize the combination of medical care, hierarchical diagnosis and treatment, resource sharing and service coordination. We will enhance the ability of grass-roots units to provide medical care for the aged and improve the health level of the people. In addition, some hospitals rely on the existing medical platform to set up unaccompanied geriatrics. According to different nursing needs, the elderly are divided into four types: self-care, semi-self-care, full nursing and hospice care.

Internal integration model of medical care in pension institutions: Due to the large investment in the early stage of this model, real estate enterprises and insurance enterprises are mainly entering this field, through the commercial real estate model, to create a combination of quality real estate and good housekeepers and to achieve the integration of living accommodation services and health management. In the whole region we can meet the needs of catering, home, sports, nursing, medical care, health and other integrated pension services.

\section{METHODOLOGY}

\section{Data source:}

The data used in this research were obtained from a self-administered or interview questionnaire survey. Participants in the questionnaire were informed consent, no cognitive impairment. A total of 430 questionnaires were sent and collected, including 404 valid questionnaires. The effective recovery rate was $93.95 \%$.

The contents of the questionnaire include: Basic information of the elderly (age, sex, education, marital status, type of job, type of health insurance, monthly income, etc.), whether suffering from chronic disease, whether to take data monitoring (wearable device), and investigating the satisfaction evaluation of community health service institutions or pension institutions. Another parts of the questionnaire include: Basic information of nursing staff (age, sex, marital status, educational background, working years, professional title, monthly income, etc.), whether they are satisfied with their current working status, whether they consider changing jobs (reasons for changing jobs), etc.

\section{Reliability and validity analysis:}

Reliability analysis:Reliability refers to the degree of consistency of the results when the same object is repeatedly measured by the same method. The reliability index is mostly expressed by correlation coefficient, which can be roughly divided into three categories: stability coefficient (cross-time consistency), equivalent coefficient (cross-formal consistency) and internal consistency coefficient (cross-project consistency). Among them, the Cronbach's alpha $(\alpha)$ coefficient, which belongs to the intrinsic consistency coefficient, is the most commonly used reliability coefficient at present, which is used to test the consistency of subject's answers to all questions in the same scale. This method is mainly used in this study.

In this study, Cronbach's $\alpha$ coefficient is 0.912 and 0.903 respectively. According to the statistical point of view, the reliability coefficient of any test or scale is between 0.70 and 0.90 , indicating that the internal consistency of the test or scale is good. The reliability coefficient of any test or scale is more than 0.90 , indicating that the internal consistency of the test or scale is very ideal. Therefore, it shows that the data of the satisfaction scale and the demand scale have a high internal consistency. 
Validity analysis: The part of the questionnaire is designed with professional literatures and the practice of others. The content and object of the survey are consistent, and the questionnaires have a basis for use. Therefore, its validity can be guaranteed.

\section{RESULTS AND DISCUSSION}

According to the "global report on aging and health" issued by the World Health Organization (WHO) in 2016, priority should be given to actions on healthy aging from the following aspects ${ }^{[22]}$. Health system should provide effective services for the elderly, establish long term care system, create a caring environment for the elderly, and improve the level of measurement, monitoring and cognition. Through the investigation on the overall supply status of pension or medical and health services in various institutions, and conducting semi-structured in-depth interviews with the government, pension institutions, medical institutions, the elderly and their families, and combining with the above mentioned principles and objectives of WHO, the institutions in the research area are paying more and more attention to the medical support, the transformation of the aging environment and the care of the elderly. The difference is obvious (Table 1 and Table 2).

The items with higher satisfaction rate of the elderly, to the services provided by medical and health institutions or pension institutions are as follows: geographical location, medical services, service response, life care, drug provision, counseling help, and institutional fees. The most dissatisfied are counseling and agency fees, as shown in Table 3.

The design of this questionnaire mainly summarizes the medical and health service needs of the elderly from the two dimensions of "doctor+care", that is, basic medical services and rehabilitation guidance services as dependent variables. The basic factors that may affect these two dimensions are taken as independent variables: age, gender, education level, occupation (before retirement), chronic diseases, marital status, ideal choice of providing for the aged, monthly income, willingness to use information technology for disease management, and so on. Through statistical methods, to study the relationship between these independent variables and dependent variables, and finally understood the impact of the basic situation of the elderly on the overall demand for medical services.

As shown by Table 4, the male-to-female ratio is equal 1 PUR 0.8 ; more than $80 \%$ of the elderly have health insurance, which is in the form of major old-age insurance and unit labor insurance (pension). Among the elderly surveyed, the largest number of $65 \mathrm{y}$ old people aged 70 was 194 , accounting for $48.0 \%$, while there were only 2 people over 90 y old, accounting for only $0.5 \%$. There were 354 elderly people with chronic diseases, accounting for $87.6 \%$, and only 50 people without disease, accounting for $12.4 \%$. It is

TABLE 1: WILLINGNESS OF STAKEHOLDERS TO PARTICIPATE

\begin{tabular}{|c|c|c|}
\hline Target & Willingness & Reason \\
\hline Government & High & $\begin{array}{l}\text { The national level attaches great importance to the construction of the pension } \\
\text { system. In } 2017 \text { and } 2018 \text {, the national "two sessions" listed it as the key work of } \\
\text { people's livelihood for two consecutive y, and made it clear that the combination of } \\
\text { medical care and nursing is the direction of future development. Local governments } \\
\text { have strong willingness to promote the pension service industry. }\end{array}$ \\
\hline $\begin{array}{l}\text { Public Nursing and } \\
\text { Medical Institution }\end{array}$ & Lower & $\begin{array}{l}\text { The main worry is that the investment is large and the efficiency is low, and more } \\
\text { responsibilities and risks need to be taken. }\end{array}$ \\
\hline $\begin{array}{l}\text { Private Nursing } \\
\text { home/Medical } \\
\text { Institution }\end{array}$ & High & $\begin{array}{l}\text { Because it is set up for the disabled and semi disabled elderly who need both pension } \\
\text { services and medical services, it has the attribute of combination of medical and } \\
\text { nursing services }\end{array}$ \\
\hline Doctors and nurses & Low & $\begin{array}{l}\text { A large number of medical practitioners or general practitioners are needed for the } \\
\text { combination of medical and nursing care, but the imbalance between supply and } \\
\text { demand is serious. The full-time doctors and nursing staff in pension institutions } \\
\text { generally think that it is difficult to improve their business, the economic treatment is } \\
\text { low and the development space is small. }\end{array}$ \\
\hline Elderly/Families & Higher & $\begin{array}{l}\text { Under the mode of combination of medical care and nursing, the elderly have been } \\
\text { guaranteed basic life and daily care, and medical care and health care services have } \\
\text { been added, and the quality of life has been significantly improved. Most of the family } \\
\text { members think that if the pension institution has the function of medical service, it } \\
\text { can not only make the elderly get the necessary medical services at the first time, but } \\
\text { also save a lot of time and energy of family members. }\end{array}$ \\
\hline
\end{tabular}




\begin{tabular}{|c|c|c|c|c|c|c|}
\hline Supporting type & \multicolumn{6}{|c|}{ Supporting level } \\
\hline Medical Service & \multicolumn{6}{|c|}{$\begin{array}{l}\text { Medical institutions with pension institutions+cooperation between pension institutions and medical } \\
\text { institutions can meet the needs of different elderly people, promote the combination of medical and } \\
\text { health care and pension services, and ensure that the elderly have access to medical care and care. }\end{array}$} \\
\hline $\begin{array}{l}\text { Suitable for aging } \\
\text { environment }\end{array}$ & \multicolumn{6}{|c|}{$\begin{array}{l}\text { Most of the integrated medical and nursing institutions have multiple functional areas to } \\
\text { provide services for the elderly, such as meal assistance, medical assistance, bath assistance, cleaning, } \\
\text { emergency assistance, spiritual comfort, University for the elderly, and home visiting services; } \\
\text { 2. Most of the institutions have achieved barrier free access and walking handrails, while some } \\
\text { institutions lack corresponding fall prevention measures for toilet and bath. The institutions and facilities } \\
\text { have a certain understanding of "internal function maintenance and external function play and repair". }\end{array}$} \\
\hline Elderly Caring & \multicolumn{6}{|c|}{$\begin{array}{l}\text { 1. Special night care services are set up in the elderly care institutions, and multiple shifts of staff } \\
\text { are on duty every night. } \\
\text { 2. The community health service center actively promotes the family "old-age care" project, and } \\
\text { provides medical, health, cultural and other aging services for the elderly through family doctor contract } \\
\text { signing, free health examination, volunteer service, health care knowledge lectures and other activities. }\end{array}$} \\
\hline $\begin{array}{l}\text { Pension } \\
\text { Conception }\end{array}$ & \multicolumn{6}{|c|}{$\begin{array}{l}\text { 1. Some areas (Fujian, Guangdong) are more exclusive to the institution pension because of the } \\
\text { deep-rooted traditional cultural concept, and they prefer to rely on their children or self-reliance; } \\
\text { 2. First tier cities are willing to give priority to institutional pension due to cultural integration, } \\
\text { relatively abundant medical, rehabilitation and pension resources and relatively developed economy; Due } \\
\text { to the primary consideration of economic affordability, the willingness to enter institutions is not very } \\
\text { high in underdeveloped areas. }\end{array}$} \\
\hline$(10)]$ & r & & & & & \\
\hline Project & Very satisfied & Satisfied & General & Dissatisfied & $\begin{array}{c}\text { Very } \\
\text { dissatisfied }\end{array}$ & $\begin{array}{c}\text { Comprehensive } \\
\text { satisfaction degree (\%) }\end{array}$ \\
\hline $\begin{array}{l}\text { jeographical } \\
\text { ocation }\end{array}$ & $140(34.7)$ & $121(30.0)$ & $107(26.5)$ & $30(7.4)$ & $6(1.5)$ & 90.84 \\
\hline Medical service & 151 (37.4) & & & & & \\
\hline Service response & $105(26.0)$ & & & & & 89 . \\
\hline Life care & 141 (34.9) & $118(29.2)$ & 105 & 34 & $6(1.5)$ & 89. \\
\hline Drug supply & $155(38.4)$ & & & & $4(1.0)$ & 88.89 \\
\hline Consult and help & $96(23.8)$ & $108(26.7)$ & 149 (36.9) & & & 87.66 \\
\hline Agency charge & $78(19.3)$ & $116(28.7)$ & $161(39.9)$ & $47(11.6)$ & $2(0.5)$ & 87.23 \\
\hline
\end{tabular}

very common for the elderly to suffer from all kinds of chronic diseases, so health management and chronic disease management will be the key direction of the combination of medical and nursing work in the future.

Five pieces of personal basic information such as age and average monthly income are taken as independent variables, in which age can be used as continuous variables, and the other four variables are classified variables. Virtual variables need to be set before analysis. The older the elderly, the more their monthly income was more than 3000 yuan, and occupation as a worker, married with chronic diseases, the more satisfied they were with their community health service institutions $(\mathrm{p}<0.05)$ as shown in Table 5.

In order to study the impact of monthly income, occupation, marriage and ideal pension choice on the demand for basic medical services and health services, and to test whether there are significant differences among different groups, a single factor analysis of variance (ANOVA) was carried out. The results are as follows.

There were significant differences in the demand for basic medical services and rehabilitation guidance services among the elderly groups with different monthly income, and passed the significant difference test (Franks 5.289 and 5.312 journal $\mathrm{p}<0.05$ ), indicating that there were significant differences in the demand for medical and health services among the elderly groups with different monthly income (Table 6).

Occupation as one of the effective channels for a person to obtain the source of income, the difference of its type is directly related to its income. In the study of Huang Fengyi et al., it is found that occupation is one of the influencing factors of mental comfort service for the elderly ${ }^{[23]}$. There were significant differences between basic medical services and rehabilitation guidance services among groups of different occupations, and passed the significance test (Fidel 5.574 and $2.325(\mathrm{p}<0.05)$, indicating that there were significant 
TABLE 4: DIFFERENCE TEST OF OVERALL SERVICE SATISFACTION OF INSTITUTIONS (x \pm s)

\begin{tabular}{|c|c|c|c|c|c|c|}
\hline \multicolumn{2}{|c|}{ Influencing factors } & \multirow{2}{*}{$\frac{n}{220}$} & \multirow{2}{*}{$\begin{array}{c}\text { Proportion (\%) } \\
54.5\end{array}$} & \multirow{2}{*}{$\begin{array}{c}\text { Total average score of } \\
\text { satisfaction } \\
3.723 \pm 0.769\end{array}$} & \multirow{3}{*}{$\begin{array}{c}\text { t or } \mathbf{f} \text { value } \\
0.007\end{array}$} & \multirow{3}{*}{$\begin{array}{c}\begin{array}{c}\mathrm{p} \\
\text { value }\end{array} \\
0.995\end{array}$} \\
\hline Gender & Male & & & & & \\
\hline Gender & Female & 184 & 45.5 & $3.683 \pm 0.754$ & & \\
\hline & $65-70$ & 194 & 48.0 & $3.924 \pm 0.741$ & & \\
\hline \multirow[t]{3}{*}{ Age } & $71-80$ & 143 & 35.4 & $3.589 \pm 0.799$ & 11.624 & 0.000 \\
\hline & $\geq 80$ & 67 & 16.6 & $3.623 \pm 0.763$ & & \\
\hline & $\leq 3000$ & 303 & 75.0 & $3.692 \pm 0.832$ & & \\
\hline \multirow[t]{2}{*}{ Monthly income } & $3000-6000$ & 68 & 16.8 & $3.787 \pm 0.563$ & 14.378 & 0.000 \\
\hline & $\geq 6000$ & 33 & 8.2 & $3.841 \pm 0.863$ & & \\
\hline \multirow{2}{*}{ Chronic diseases } & Yes & 354 & 87.6 & $3.963 \pm 0.771$ & 3.574 & 0,000 \\
\hline & No & 50 & 12.4 & $3.852 \pm 0.788$ & & \\
\hline \multirow{5}{*}{$\begin{array}{l}\text { Type of medical } \\
\text { insurance }\end{array}$} & Medical insurance & 326 & 80.7 & $3.987 \pm 0.723$ & & \\
\hline & Free medical treatment & 50 & 12.4 & $3.664 \pm 0.768$ & & \\
\hline & $\begin{array}{l}\text { Commercial medical } \\
\text { insurance }\end{array}$ & 6 & 1.5 & $3.754 \pm 0.852$ & 7.558 & 0.000 \\
\hline & Other & 2 & 0.5 & $3.324 \pm 0.851$ & & \\
\hline & None of the above & 20 & 5.0 & $3.456 \pm 0.777$ & & \\
\hline \multirow{7}{*}{ Occupation } & Cadres & 110 & 27.2 & $3.974 \pm 0.865$ & & \\
\hline & Farmers & 153 & 37.9 & $3.654 \pm 0.852$ & & \\
\hline & soldier & 30 & 7.4 & $3.752 \pm 0.874$ & & \\
\hline & Self-employed & 48 & 11.9 & $3.741 \pm 0.863$ & 7.651 & 0.000 \\
\hline & Workers & 18 & 4.5 & $3.663 \pm 0.788$ & & \\
\hline & Be unemployed & 42 & 10.4 & $3.245 \pm 0.753$ & & \\
\hline & & 3 & 0.7 & $3.687 \pm 0.772$ & & \\
\hline \multirow{5}{*}{ Marital status } & Married & 240 & 59.4 & $3.912 \pm 0.774$ & & \\
\hline & Bereaved a spouse & 114 & 28.2 & $3.852 \pm 0.796$ & & \\
\hline & Divorce & 11 & 2.7 & $3.665 \pm 0.785$ & 6.241 & 0.000 \\
\hline & Long term separation & 16 & 4.0 & $3.412 \pm 0.764$ & & \\
\hline & Other & 23 & 5.7 & $3.212 \pm 0.772$ & & \\
\hline
\end{tabular}

TABLE 5: MULTIPLE REGRESSION ANALYSIS OF THE INFLUENCING FACTORS OF OVERALL SATISFACTION OF THE ELDERLY

\begin{tabular}{|c|c|c|c|c|c|c|c|}
\hline Factors & Test group & $\begin{array}{l}\text { Reference } \\
\text { group }\end{array}$ & B & B & $\mathrm{t}$ value & $p$ value & $\begin{array}{l}95.0 \% \text { confidence } \\
\text { interval }(\mathrm{Cl})\end{array}$ \\
\hline Constant & - & - & 2.785 & - & 6.635 & 0.000 & $1.523 \sim 2.695$ \\
\hline Age & - & - & 0.023 & 0.245 & 5.236 & 0.000 & $0.032 \sim 0.042$ \\
\hline Occupation & Workers & Cadres & 0.236 & 0.123 & 3.695 & 0.000 & $0.123 \sim 0.289$ \\
\hline chronic disease & No & Yes & -0.233 & -0.059 & -2.369 & 0.023 & $-0.352 \sim-0.009$ \\
\hline Marital status & $\begin{array}{l}\text { Bereaved a } \\
\text { spouse }\end{array}$ & Married & -0.539 & -0.113 & -2.694 & 0.000 & $-0.965 \sim-0.123$ \\
\hline Monthly income & $\geq 3000$ & $\leq 3000$ & -0.456 & -0.214 & -4.963 & 0.000 & $-0.548 \sim-0.231$ \\
\hline
\end{tabular}

TABLE 6: ONE-WAY ANOVA OF THE MEAN AMONG PEOPLE WITH DIFFERENT IDEAL WAYS OF PROVIDING FOR THE AGED

\begin{tabular}{lccccccc}
\hline Factors & & N & Mean value & Standard deviation & Standard error & $\mathbf{f}$ & $\mathbf{P}$ \\
\hline & $\leq 3000$ & 303 & 3.8650 & 0.86384 & 0.28542 & 5.289 & 0.002 \\
Basic medical & $3000-6000$ & 68 & 3.5428 & 0.67389 & 0.15244 & 0.20021 & \\
service & $\geq 6000$ & 33 & 3.7779 & 0.52865 & 0.06986 & 5.312 \\
& Total & 404 & 3.7286 & 0.793280 & 0.26870 & 0.035 \\
Rehabilitation & $\leq 3000$ & 303 & 3.5629 & 0.96320 & 0.55745 & \\
guidance & $3000-6000$ & 68 & 3.3256 & 0.75293 & 0.55748 & \\
service & $\geq 6000$ & 33 & 3.4236 & 0.88524 & 0.35690 & & \\
& Total & 404 & 3.4374 & 0.85231 & &
\end{tabular}


differences among groups of different occupations (Table 7).

There was no significant difference in the average values of basic medical services and rehabilitation guidance services among people with different marital status, and the results of one-way ANOVA showed that they did not pass the significance test (Fair 1.444 and $1.324 \mathrm{p}>0.05$ ), indicating that marital status did not constitute an important factor affecting basic medical services and rehabilitation guidance services (Table 8).
The groups with different ideal ways of providing for the aged have obvious differences in the demand for basic medical services, and have passed the significant difference test (Fend 5.237). It shows that there are significant differences in basic medical services among groups with different ideal ways of providing for the aged. The study was further tested by least significant difference (LSD) after multiple comparisons, and the results showed that there were significant differences in basic medical services among groups with different

TABLE 7: ONE-WAY ANOVA ANALYSIS OF THE DEMAND FOR BASIC MEDICAL SERVICES AND REHABILITATION GUIDANCE SERVICES IN DIFFERENT OCCUPATIONS

\begin{tabular}{lcccccc}
\hline Factors & & $\mathrm{N}$ & Mean value & Standard deviation & $\mathrm{f}$ & $\mathrm{P}$ \\
\hline \multirow{5}{*}{ Basic medical service } & Cadres & 110 & 4.0632 & 0.79656 & 5.574 & 0.000 \\
& Farmers & 153 & 3.5697 & 0.67732 & & \\
& Workers & 30 & 4.0122 & 0.72311 & & \\
& Self-employed & 48 & 3.6968 & 0.65853 & & \\
& soldier & 18 & 4.1867 & 0.61975 & & \\
Rehabilitation & Be unemployed & 42 & 3.6163 & 0.81822 & & \\
guidance service & Other & 3 & 3.4578 & 0.63248 & & \\
& Total & 404 & 3.8450 & 0.043 \\
& Cadres & 110 & 3.9048 & 0.83183 & 2.325 & \\
& Farmers & 153 & 3.4957 & 0.75934 & & \\
& Workers & 30 & 3.6333 & 0.83301 & & \\
& Self-employed & 48 & 3.5714 & 0.58670 & & \\
& soldier & 18 & 3.7238 & 0.58020 & & \\
& Be unemployed & 42 & 3.4120 & 10.02790 & & \\
& Other & 3 & 3.6951 & 0.57423 & & \\
& Total & 404 & 3.6211 & 0.82557 & & \\
\hline
\end{tabular}

TABLE 8: DESCRIPTION STATISTICS OF BASIC MEDICAL SERVICES AND REHABILITATION GUIDANCE SERVICES FOR PEOPLE WITH DIFFERENT MARITAL STATUS

\begin{tabular}{lcccccc}
\hline Factors & & $\mathrm{N}$ & Mean value & Standard deviation & $\mathrm{f}$ & $\mathrm{P}$ \\
\hline & Married & 240 & 3.8910 & 0.77366 & 1.444 & 0.219 \\
& Bereaved a spouse & 114 & 3.6954 & 0.73812 & & \\
Basic medical service & Divorce & 11 & 3.9778 & 0.64220 & & \\
& Long-term & 16 & 3.3800 & 0.61400 & & \\
& separation & & & & \\
Other & 23 & 3.8000 & 0.56569 & & \\
Rehabilitation guidance & Total & 404 & 3.8450 & 0.75880 & & \\
service & Married & 240 & 3.6503 & 0.82050 & 1.324 & \\
& Bereaved a spouse & 114 & 3.4462 & 0.88659 & & \\
& Divorce & 11 & 3.8413 & 0.61179 & & \\
& Long-term & 16 & 3.6571 & 0.81816 & & \\
& separation & & & & \\
& Other & 23 & 4.1429 & 0.40406 & & \\
& Total & 404 & 3.6211 & 0.82557 & & \\
\hline
\end{tabular}


ideal ways of providing for the aged. Community home medical needs (such as suffering from chronic diseases, semi self-care or unable to take care of themselves, etc.), the group demand for old age care is significantly greater than the community ordinary home based pension needs, the other differences are not significant. There was no significant difference in the demand for rehabilitation guidance services among the groups with different ideal pension styles, and there was no significant difference in the rehabilitation guidance services among the groups with different ideal pension styles (Table 9).

Family providing for the aged, community living at home and providing for the aged with medical needs at home are the mainstream ways for the elderly to choose at this stage ${ }^{[24]}$. The results of this survey show that $69.3 \%$ of the elderly prefer to stay at home for the aged, $12.4 \%$ of the elderly choose to stay at home for the aged in the community, and only 16 people $(4.0 \%)$ receive institutional pension. It shows that the traditional concept of "raising children to prevent old age" has gone deep into the hearts of the elderly, and the care and care of their families is still the destination of the elderly.

In order to analyze whether there are significant differences in the needs of basic medical services and health guidance services between people of different genders, people with and without chronic diseases, people who are willing and unwilling to use information-based means for disease management, through independent sample T-test, the results are as follows.

There was no significant difference in the demand for basic medical services and rehabilitation guidance services between male and female groups, and did not pass the significance test $(\mathrm{p}>0.05)$, indicating that there was no significant difference between different genders (Table 10).

There are great differences in basic medical services and rehabilitation guidance services between groups with and without chronic diseases, and passing the significance test $(\mathrm{p}<0.05)$ shows that there are significant differences between groups with and without chronic diseases. Specifically, through the mean, it can be seen that the average value of basic medical services and rehabilitation guidance services in the group with chronic disease is significantly higher than that in the group without chronic disease. It shows that people with chronic diseases have a stronger demand (Table 11).

TABLE 9: ONE-WAY ANOVA OF THE MEAN AMONG PEOPLE WITH DIFFERENT IDEAL WAYS OF PROVIDING FOR THE AGED

\begin{tabular}{|c|c|c|c|c|c|c|c|}
\hline Factors & & $\mathbf{N}$ & Mean value & Standard deviation & Standard error & $f$ & $\mathrm{p}$ \\
\hline \multirow{5}{*}{$\begin{array}{l}\text { Basic medical } \\
\text { service }\end{array}$} & Institutional pension & 16 & 3.7000 & 0.95394 & 0.28762 & 5.237 & 0.002 \\
\hline & Family providing for the aged & 280 & 3.8858 & 0.75301 & 0.04944 & & \\
\hline & $\begin{array}{c}\text { Community living at home } \\
\text { for the aged }\end{array}$ & 50 & 3.4459 & 0.62964 & 0.10351 & & \\
\hline & $\begin{array}{l}\text { Community home medical } \\
\text { care for the aged }\end{array}$ & 58 & 4.1591 & 0.69943 & 0.14912 & & \\
\hline & Total & 404 & 3.8450 & 0.75880 & 0.04366 & & \\
\hline \multirow{5}{*}{$\begin{array}{l}\text { Rehabilitation } \\
\text { guidance } \\
\text { service }\end{array}$} & Institutional pension & 16 & 3.7143 & 1.02020 & 0.30760 & 1.052 & 0.370 \\
\hline & Family providing for the aged & 280 & 3.6490 & 0.81863 & 0.05375 & & \\
\hline & $\begin{array}{c}\text { Community living at home } \\
\text { for the aged }\end{array}$ & 50 & 3.3977 & 0.73164 & 0.12028 & & \\
\hline & $\begin{array}{l}\text { Community home medical } \\
\text { care for the aged }\end{array}$ & 58 & 3.6558 & 0.93901 & 0.20020 & & \\
\hline & Total & 404 & 3.6211 & 0.82557 & 0.04751 & & \\
\hline
\end{tabular}

TABLE 10: A TEST OF THE DIFFERENCES IN THE NEEDS OF PEOPLE OF DIFFERENT GENDERS

\begin{tabular}{|c|c|c|c|c|c|c|}
\hline Factors & Gender & $\mathbf{N}$ & Mean value & Standard deviation & $\mathbf{t}$ & $\mathbf{p}$ \\
\hline \multirow{2}{*}{ Basic medical service } & Male & 220 & 3.8636 & 0.72137 & 0.467 & 0.641 \\
\hline & Female & 184 & 3.8226 & 0.80367 & & \\
\hline \multirow[t]{2}{*}{ Rehabilitation guidance service } & Male & 220 & 3.6926 & 0.74709 & 1.658 & 0.098 \\
\hline & Female & 184 & 3.5349 & 0.90650 & & \\
\hline
\end{tabular}


The demand degree of the groups who are willing to use information means to intervene in diseases is greater than those who do not want to use information means to intervene, and the mean values between them have passed the significance test $(p<0.05)$. It shows that the demand for basic medical services and rehabilitation guidance services of people who are willing to use information means for disease detection and management is significantly higher than those who are not willing to use information means to intervene, detect and manage diseases (Table 12).

In order to study the effects of age, education level and monthly income on health services, a linear regression model was established, with the demand for health services as dependent variables and age, education level and income as independent variables (Table 13).

The results showed that the goodness-of-fit of the model was $\mathrm{R}^{2}=0.09$, and the statistic of analysis of variance was 9.841, and passed the significance test $(\mathrm{F}=9.814, \mathrm{p}<0.05)$. It shows that there is a significant linear relationship between the dependent variables and the independent variables of the model, and the model is statistically significant. From the test results of the significance of the coefficient, it can be seen that among the three variables of age, education level and monthly income, the coefficients of age $(\mathrm{t}=4.411, \mathrm{p}<0.05)$ and income $(\mathrm{t}=2.061, \mathrm{p}<0.05)$ pass the significance test, indicating that age and monthly income have a significant impact on basic medical services, and the coefficient is positive, indicating that with the increase of age and monthly income, the demand for basic medical services will also increase.

In order to analyze the influence of age, monthly income and education level on rehabilitation guidance service, a regression model was established with age, monthly income and education level as independent variables and rehabilitation guidance service as dependent variable. The results showed that the goodness-of-fit of the model was $\mathrm{R}^{2}=0.061$, and the statistic of analysis of variance was 6.500 , and passed the significance test $(\mathrm{F}=6.500, \mathrm{p}<0.05)$, indicating that there was a significant linear relationship between the dependent variable and the independent variable as a whole, and the model was statistically significant. By observing the significance of the model coefficient, we can see that among the three variables of age, education

TABLE 11: TEST ON THE DIFFERENCE OF PEOPLE WITH CHRONIC DISEASES

\begin{tabular}{|c|c|c|c|c|c|c|}
\hline Factors & $\begin{array}{l}\text { Willing to use information technology to } \\
\text { intervene, monitor or manage diseases }\end{array}$ & $\mathbf{N}$ & $\begin{array}{l}\text { Mean } \\
\text { value }\end{array}$ & $\begin{array}{l}\text { Standard } \\
\text { deviation }\end{array}$ & $\mathrm{t}$ & $\mathrm{p}$ \\
\hline \multirow{2}{*}{ Basic medical service } & Willing & 293 & 3.5623 & 0.69583 & 4.523 & 0.034 \\
\hline & Unwilling & 111 & 3.9625 & 0.89632 & & \\
\hline \multirow[t]{2}{*}{$\begin{array}{l}\text { Rehabilitation } \\
\text { guidance service }\end{array}$} & Willing & 293 & 3.2659 & 0.65932 & 1.958 & 0.021 \\
\hline & Unwilling & 111 & 3.2133 & 0.79521 & & \\
\hline
\end{tabular}

TABLE 12: WILLING AND UNWILLING TO USE INFORMATION TECHNOLOGY TO DESCRIBE THE NEEDS OF DISEASE MANAGEMENT POPULATION

\begin{tabular}{|c|c|c|c|c|c|c|}
\hline Factors & $\begin{array}{l}\text { Willing to use information technology to } \\
\text { intervene, monitor or manage diseases }\end{array}$ & $\mathbf{N}$ & $\begin{array}{l}\text { Mean } \\
\text { value }\end{array}$ & $\begin{array}{l}\text { Standard } \\
\text { deviation }\end{array}$ & $\mathrm{t}$ & $\mathbf{p}$ \\
\hline \multirow{2}{*}{ Basic medical service } & Willing & 293 & 3.5623 & 0.69583 & 4.523 & 0.034 \\
\hline & Unwilling & 111 & 3.9625 & 0.89632 & & \\
\hline \multirow[t]{2}{*}{$\begin{array}{l}\text { Rehabilitation } \\
\text { guidance service }\end{array}$} & Willing & 293 & 3.2659 & 0.65932 & 1.958 & 0.021 \\
\hline & Unwilling & 111 & 3.2133 & 0.79521 & & \\
\hline
\end{tabular}

TABLE 13: REGRESSION ANALYSIS OF FACTORS AFFECTING THE DEMAND FOR BASIC MEDICAL SERVICES

\begin{tabular}{|c|c|c|c|c|c|}
\hline \multirow{2}{*}{ Model } & \multicolumn{2}{|c|}{ Non-standardized coefficient } & \multirow{2}{*}{ Standard coefficient } & \multirow{2}{*}{$\mathrm{t}$} & \multirow{2}{*}{ Significance } \\
\hline & B & Standard error & & & \\
\hline (Constant) & 1.811 & 0.437 & & 4.144 & 0.000 \\
\hline Age & 0.026 & 0.006 & 0.248 & 4.411 & 0.000 \\
\hline degree of education & 0.016 & 0.035 & 0.029 & 0.449 & 0.654 \\
\hline Monthly income & 0.551 & 0.267 & 0.134 & 2.061 & 0.040 \\
\hline
\end{tabular}

Dependent variable: basic medical services, Model result: $R^{2}=0.09(f=9.841, p<0.05)$ 
level and monthly income, the coefficients of age $(\mathrm{t}=2.508, \mathrm{p}<0.05)$ and income $(\mathrm{t}=3.143, \mathrm{p}<0.05)$ pass the significance test, indicating that it has a significant impact on rehabilitation guidance services, and its coefficient is positive. It shows that with the increase of age and income, the demand for rehabilitation guidance services of the elderly will also show an upward trend (Table 14).

According to the analysis of the above results, age, income, occupation, whether suffering from chronic diseases, whether they are willing to use informationbased means for disease detection and management and other factors, all affect the needs of the elderly for basic medical services and rehabilitation guidance services in medical service institutions.

The results showed that the age, monthly income and chronic diseases of the elderly at home were all factors affecting the intensity of demand for medical and health services (basic medical services and rehabilitation guidance services). And with the increase of age and income, the demand for (close) health services of the elderly at home who suffer from chronic diseases will also increase. The results of these two studies are consistent with the studies of Wang Yuqiu and $\mathrm{Xu}$ Guoqiang, who believe that age and economic level have a significant impact on residents demand for medical services ${ }^{[25]}$.

For the older the elderly, their physical function tends to be weak, and their chances of suffering from chronic diseases are increasing, both in terms of mobility and cognitive ability. As a result, they are more likely to rely on medical institutions that are geographically closer (such as community health services). It may be necessary to carry out basic medical and health services such as blood pressure measurement in the institution at any time, or services such as mobility difficulties, and regular rehabilitation guidance for elderly people who rest after surgery, which is consistent with Li Haiying's research. It is considered that chronic disease is one of the important factors affecting the health of the middleaged and elderly ${ }^{[26]}$.

For the elderly with higher income, the results of many studies show that there is a positive correlation between willingness to pay and economic status ${ }^{[27]}$. Because the elderly with higher income generally have less economic pressure than the low-income elderly, they pay more attention to their own physical quality on the basis of ensuring the quality of life, and are more willing to obtain higher quality medical and health services at higher prices. Therefore, the higher the demand for various medical services provided by community medical and health service institutions.

Occupation as one of the effective channels for a person to obtain the source of income, the difference of its type is directly related to its income. In the study of Huang Fengyi et al., it is found that occupation is one of the influencing factors of mental comfort service for the elderly ${ }^{[23]}$. The results of this study further show that the type of occupation of the elderly before retirement significantly affects their demand for basic medical services and rehabilitation guidance services in community medical and health institutions. In particular, the demand for medical and health services of the elderly who have worked in state organs, party and mass organizations, enterprises, institutions and other "golden rice bowl" units before retirement is higher than that of other occupational groups such as cadres and employees of public institutions, workers and military personnel and other three professional groups. To a large extent, it is because different types of occupational groups receive different retirement wages and medical security benefits provided by state units and enterprises after retirement. According to the average level of pension obtained from this survey, the staff and workers of the highest institutions (deputy high professional title) are more than 6000 yuan, followed by civil servants (bachelor's degree, department level) more than 3700 yuan. The least is the retired employees working in the enterprise (40 y of service) only more

TABLE 14: REGRESSION ANALYSIS OF INFLUENCING FACTORS OF REHABILITATION GUIDANCE SERVICE DEMAND

\begin{tabular}{lccccc}
\hline \multirow{2}{*}{ Model } & \multicolumn{2}{c}{ Non-standardized coefficient } & \multirow{2}{*}{ Standard coefficient } & $\mathrm{t}$ & \multirow{2}{*}{ Significance } \\
\cline { 2 - 3 } (Constant) & $\mathrm{B}$ & Standard error & & 4.866 & 0.000 \\
Age & 2.350 & 0.483 & & 2.508 & 0.013 \\
degree of education & 0.016 & 0.006 & 0.143 & -0.990 & 0.323 \\
Monthly income & -0.038 & 0.038 & -0.065 & 3.143 & 0.002 \\
\hline
\end{tabular}

Dependent variable: rehabilitation guidance service, Model result: $R^{2}=0.061(f=6.500, p<0.05)$ 
than 2800 yuan. And for the reimbursement of medical expenses after retirement, according to different occupations, the proportion of reimbursement is also different, and for the elderly in state owned enterprises or institutions before retirement, they can sometimes enjoy free medical care. Therefore, under the dual insurance of stable income and public health care, the elderly in this group pay more attention to the extension of life, so the demand for medical and health services is higher than that of other groups.

Family pension, community home care and community home medical care are the mainstream ways of providing for the aged at the present stage ${ }^{[2]}$. In this study, the specific results show that the choice of different ideal pension methods only has a significant impact on the demand for basic medical services, and the largest demand is for those who need medical care at home in the community, followed by family pension. The third is institutional pension, and the lowest is community based pension. However, it did not have a significant impact on the demand for rehabilitation guidance services. Because compared with other simple institutions that only provide life care services, the elderly who choose community home and medical care for the aged pay more attention to medical services and life care as a whole. This way not only takes into account the family pension psychology of having children "filial piety for a $100 \mathrm{~d}$ before bed", which the elderly rely on for a long time, but also on the basis of providing timely life care. It can cooperate with the medical and health service institutions in the community, which is the closeness of medical care and it can also solve the problem that the elderly are far away from seeing a doctor and tired of seeing a doctor. To a large extent, to protect the health of the elderly combined with the results of the respondents highest satisfaction with various services is the "geographical location", being able to obtain medical services nearby is the most concerned factor for the elderly. Therefore, the elderly with the above considerations pay particular attention to survival and quality of life, thus the higher the level and demand for basic medical services provided by medical and health service institutions.

Whether they have health-related wearable devices and whether they are willing to use information-based means to detect and manage diseases to a certain extent affect the choice of medical and health services for the elderly (basic+rehabilitation). Under the influence of the "graded diagnosis and treatment system" of the current "five systems" of basic medical and health care, "family doctor signing" has become the cornerstone of the effective implementation of this system. In fact, whether they have health-related wearable devices and whether they are willing to use information-based means to monitor and manage diseases is also part of the technical support of family doctors, that is, informationbased support, through information sharing to establish the health files of elderly residents to achieve the purpose of timely communication between doctors and doctors, doctors and patients, as well as mobile devices to support the elderly for health management and other methods. At the same time of realizing the construction of regional medical information, family doctors can intelligently manage their contracted service objects in order to reduce the workload caused by signing contracts.

With the implementation of the "Family Doctor contract", the demand for medical services for the elderly can be realized by a series of customized medical services such as door to door diagnosis and treatment provided by a professional medical team composed of general practitioners, nurses and public health physicians in contracted medical institutions, but these services are based on the premise that patients have to pay a certain fee, although the amount is not high, according to consumer psychology. People need to meet their own money and other costs through commodities to achieve psychological balance, and the final difference in their own needs of commodities is an important reason that affects the psychological balance. On the other hand, the elderly who have health-related equipment and are willing to use information-based means to monitor diseases (or their immediate family members) have relatively higher ability to pay and pay more attention to medical convenience. Therefore, this group has a corresponding increase in the demand for basic medical services and rehabilitation guidance services provided by contracted medical institutions.

In summary, age, income, occupation, whether suffering from chronic diseases, whether they are willing to use information technology to detect and manage diseases and other factors, all affect the demand of the elderly for basic medical services and rehabilitation guidance services in medical service institutions.

With the increase of age and income, the intensity of demand for (close) medical and health services of the elderly at home suffering from chronic diseases will also increase. The higher the income of the elderly, the higher the demand for various medical services 
provided by community medical and health service institutions.

The type of occupation of the elderly before retirement significantly affects their demand for basic medical services and rehabilitation guidance services in community medical and health institutions. In particular, the demand for medical and health services of the elderly who have worked in state organs, party and mass organizations, enterprises, institutions and other "golden rice bowl" units before retirement is higher than that of other occupational groups. For example, the groups of three occupations, such as cadres, employees of public institutions, workers and soldiers.

The choice of different ideal ways of providing for the aged only has a significant impact on the demand for basic medical services, and the way of providing for the aged is that the groups with medical needs at home in the community have the greatest demand, followed by family pension, the third is institutional pension, and the lowest is community home pension. There is no significant impact on the demand for rehabilitation guidance services.

Whether they have health-related wearable equipment and whether they are willing to use information-based means for disease detection and management affect the demand choice of medical and health services for the elderly to a certain extent (basic+rehabilitation). Under the influence of the "graded diagnosis and treatment system" of the current "five systems" of basic medical and health care, "family doctor signing" has become the cornerstone of the effective implementation of this system. Since the epidemic of COVID-19, the elderly have always been a high-risk group of COVID-19 infection. Combined with the specific domestic situation, learn from foreign experience, implement COVID-19 epidemic prevention and control measures in medical institutions and pension institutions. Consider the influencing factors of the combination of medical and nursing, and strengthen the service mode of the combination of medical and nursing.

\section{Acknowledgements:}

We would like to thank Dr. Xuanxuan Wang for having prepared the vehicle used in the study. We are grateful to Dr. Xiaowei Wu, Dr. Zheng Wang for reviewing the manuscript.

\section{Funding:}

This research was supported by youth program of highend science and technology in-novation think tank of Chinese Association for Science and Technology (DXB-ZKQN-2017-043).

\section{Conflict of interests:}

The authors declared no conflict of interest.

\section{REFERENCES}

1. McMichael TM, Currie DW, Clark S, Pogosjans S, Kay M, Schwartz NG, et al. Epidemiology of Covid-19 in a longterm care facility in King County, Washington. N Engl J Med 2020;382(21):2005-11.

2. Portrait F, Lindeboom M, Deeg D. The use of long-term care services by the Dutch elderly. Health Econ 2000;9(6):513-31.

3. Home-Based Long-Term Care. World Health Organization, report of a WHO study group, WHO technical report series $2000 ; 898$.

4. Williams AM, Wang L, Kitchen P. Differential impacts of care-giving across three caregiver groups in Canada: end-oflife care, long-term care and short-term care. Health Soc Care Community 2014;22(2):187-96.

5. Verbeek H, Gerritsen DL, Backhaus R, de Boer BS, Koopmans RT, Hamers JP. Allowing visitors back in the nursing home during the COVID-19 crisis: A Dutch national study into first experiences and impact on well-being. J Am Med Dir Assoc 2020;21(7):900-4.

6. Stall NM, Farquharson C, Fan-Lun C, Wiesenfeld L, Loftus CA, Kain D, et al. A hospital partnership with a nursing home experiencing a COVID-19 outbreak: description of a multiphase emergency response in Toronto, Canada. J Am Geriatr Soc 2020;68(7):1376-81.

7. Abrams HR, Loomer L, Gandhi A, Grabowski DC. Characteristics of US nursing homes with COVID-19 cases. J Am Geriatr Soc 2020;68(8):1653-6.

8. Szczerbinska K. Could we have done better with COVID-19 in nursing homes? Eur Geriatr Med 2020;11:639-43.

9. Gilissen J, Pivodic L, Unroe KT, Van den Block L. International COVID-19 palliative care, guidance for nursing homes leaves key themes unaddressed. J Pain Symptom Manage 2020;60(2):e56-69.

10. Bern-Klug M, Beaulieu E. COVID-19 highlights the need for trained social workers in nursing homes. J Am Med Dir Assoc 2020;21(7):970-2.

11. Aidoud A, Poupin P, Gana W, Nkodo JA, Debacq C, Dubnitskiy-Robin $\mathrm{S}$, et al. Helping nursing homes to manage the COVID-19 crisis: an illustrative example from France. J Am Geriatr Soc 2020;68(11):2475-7.

12. Statistical bulletin of national economic and social development in 2018. Chinainnovationfunding.eu; 2018.

13. Zhuozhao T. How to provide for the aged in $20 \mathrm{y}$ time. Introduction to sociology-2nd Canadian edition; 2016.

14. Fengmei $\mathrm{Z}$, Ziqiang $\mathrm{M}$. The connotation, present situation and predicament of "combination of medicine and nursing" under the background of aging. China Health Economy; 2018.

15. Zheng H, Wang M, Zhao Y. Analysis of the current situation, problems and countermeasures of the pension model of "combination of medicine and care" in China. Chin Public Health 2018;34:1-4.

16. Yuan LC. Comparative advantages, constraints and promotion strategies of community home-based medical and nursing service model. Ningxia Soc Sci 2018;12:161-7.

17. Global pension survey-exploring the old-age code of countries 
around the world. Shanghai Radio and Television Station; 2020.

18. Dang J. Blue Book on the elderly: an investigation report on the living conditions of the elderly in Urban and Rural areas of China. Beijing: social Science Literature Press; 2018.

19. Che R. A review of the research on the mode of combination of medicine and nursing at home and abroad. Sci Technol Inf 2017;15:196-9.

20. Chen K, Shixue L. Study on the Feasibility, difficulties and Countermeasures of the Model of Integrated Medical and Nursing Care for the aged. Guizhou Soc Sci 2018;340:65-70.

21. Jiao J, Wang G. Study on the innovative model of medical and nursing care combined with pension institutions under the collaborative concept. Chin J Soc Med 2014;31:376-8.

22. Du P, Dong T. Promoting healthy aging: Concept change and policy innovation. Sci Res Aging 2015;12:3-10.

23. Wang Y, Wang S. Advances in microcosmic empirical analysis of residents medical service demand and its influencing factors. Chin Health Policy Res 2010;3:55-62.

24. Fan S, Guo H, Dong X. Research Progress on the Model of providing for the aged in China. Chin J Gerontol 2019,39:9969.

25. Wan X, He Y, Huang X. A qualitative study on the influencing factors of home care service demand and willingness to pay for the elderly. Nurs Res 2013;27:977-9.

26. Haiying L. Study on the demand and Utilization of outpatient Service and its influencing factors among Middle-aged and elderly people in Chongqing. Southwest Univ Finance Econ; 2016.

27. Asfaw A, Von Braun J. Can community health insurance schemes shield the poor against the downside health effects of economic reforms? The case of rural Ethiopia. Health policy 2004;70(1):97-108. 